\title{
SEISMIC ASSESSMENT OF HERITAGE BUILDINGS IN BULGARIA
}

\author{
MARINA D. TRAYKOVA ${ }^{1 *}$, ALEXANDER V. TRAYKOV ${ }^{2}$ \\ ${ }^{1}$ University of Architecture, Civil Engineering and Geodesy (UACEG) \\ Faculty of Structural Engineering \\ 1, Hristo Smirnenski Blvd., 1046 Sofia, Bulgaria \\ e-mail: marina5261@abv.bg, www.uacg.bg (*corresponding author) \\ ${ }^{2}$ University of Architecture, Civil Engineering and Geodesy (UACEG) \\ Faculty of Structural Engineering \\ 1, Hristo Smirnenski Blvd., 1046 Sofia, Bulgaria \\ e-mail: traykovalexander@gmail.com, www.uacg.bg
}

Keywords: Historical Structure, Seismic Assessment, Computer Modelling

\begin{abstract}
Earthquakes are some of the most serious causes of degradation and destruction of the heritage buildings. The earthquake can cause different damages, directly and indirectly to the historical buildings and their elements. The biggest part of the heritage buildings was built essentially following empirical rules, refining the proportions of structural elements by an intuitive perception of the structural behaviour. In most cases, this trial took only static actions into consideration, so, since seismic horizontal actions modify the behaviour in a significant way, an earthquake may frequently produce cracks and local collapses. Seismic assessment of heritage buildings is relevant for any preservation project. Using specific investigations and checks, the best retrofit method can be chosen. Based on different case studies, the aim of the paper is to recommend useful framework and easy applicable assumptions for practicing engineers to evaluate the vulnerability of the historic structures and the possibilities of further steps in their development. Seismic assessment of historic buildings remains a challenging task. There is a high level of complexity compared with the assessment of standard buildings. The assessment and the diagnosis of heritage buildings in seismic areas require an extensive knowledge on the structural typologies and behaviour of heritage buildings. The investigation on previous damages from earthquakes is very important. Adequate and realistic computer modelling of complicated historic structures requires significant designers' expertise. It is probably best to start with the simplest realistic model and then, if necessary, develop a model that reflects more structural features and complexity. The presented paper investigates the challenges posed by, and solutions needed, to ensure the structural longevity of historic structures. Finding the potential for future development of heritage buildings is an important task of the contemporary construction sector. The paper presents only 3 specific case studies but based on the results it is possible to produce some more general recommendations concerning the seismic assessment, the possibility to identify the vulnerability of historic structures and to give the recommendations for extending the service life of Heritage buildings.
\end{abstract}




\section{INTRODUCTION}

Buildings and structures may be classified as historic for three main reasons: they are associated with acts of historical importance, they are old and a long time has passed since their construction, and they are monumental and irreplaceable. What makes it an edifice that must be preserved for future generations are one or more of its cultural, architectural, symbolic, social or historic attributes. Studies of the seismic vulnerability of historic buildings and attempts to mitigate the associated hazards [whether by retrofitting or other procedures] and improve both the load resisting capacity and the longevity of such structures are therefore of great interest.

The assessment and the diagnosis of heritage buildings in seismic areas require an extensive knowledge on the structural typologies and behaviour of heritage buildings. The investigation on previous damages from earthquakes is very important. The presented paper investigates the challenges posed by, and solutions needed, to ensure the structural longevity of historic structures.

The main cause of the inappropriate choices of intervention techniques is due to the lack of knowledge on the material and the behaviour of the peculiar type of structure. To provide the best assessment and to collect properly the data, it is necessary to have enough information concerning: 1) the geometrical, technological and constructive characteristics of the surveyed structure; 2) the material properties; 3) past interventions; 4) the damage state, the possible collapse mechanisms. The information above is possible to be collected after a special on site investigation.

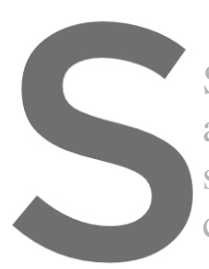

The survey on the Structural symmetry; 3 ) and material); 6) Struct structural elements: 8) L ateral characteristics; 9) Daina

The steps to be followed for the assessment may therefore
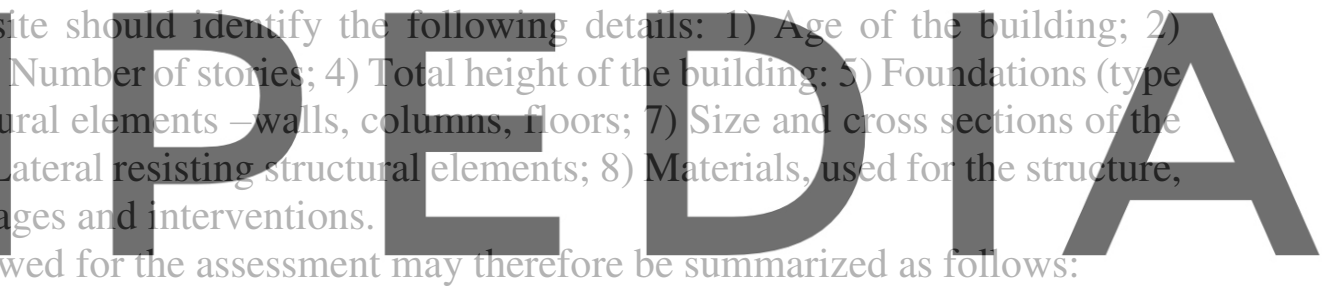

- Identify the structural characteristics of the structure under consideration, that is, the way

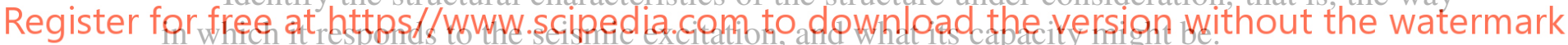

Diagnose the evidence of present structural condition, both visible and concealed. Do the necessary investigations for this diagnosis, including assessment of foundation conditions.

- Make complementary assessment of the local seismic hazard.

- Decide whether temporary shoring is needed to safeguard a damaged structure before, during and after rehabilitation.

- Propose and justify schemes for final repair and strengthening. Prepare the necessary documentation for the selected scheme, in cooperation with other experts if necessary.

During the above architectural/structural survey, a detailed analysis of structural failures, local or otherwise, a thorough study of cracks, the nature of the soil, faults in the original structure, defects of construction, shifting of the foundations, signs of excessive stresses, defective components, etc. should be carefully investigated. For most important edifices, a photogrammetric survey utilizing laser technology may be appropriate.

\section{SEISMIC RISK IN BULGARIA}

Seismic hazard [1] represents the probability of seismic earth movements to exceed a given seismic level over a certain period of time. The seismic hazard is presented through maps with 
expected seismic impacts for a different period of occurrence.

Seismic risk [1] is the probability of occurrence of given losses over a given period of time for a given location as a result of an earthquake.

The assessment of the seismic risk establishes:

- the expected losses according to the seismic impact;

- whether sufficient preventive measures have been taken to reduce the impact of the seismic actions.

Bulgaria is located in the central part of the Balkan Peninsula, which from the tectonic point of view is an element of the Eurasian continental border. The earthquake activity on the territory of the country and its surroundings is one of the most prominent manifestations of modern regional geodynamics.

The seismic situation of the Balkans has some specific aspects. The origin of most of the earthquakes that affect Bulgarian territory are shallow with focus that is less than $60 \mathrm{~km}$ in depth. That fact significantly increases the effects of the earthquakes on surface.

According to the 1987 standard map of Bulgaria, 98\% of the territory of Bulgaria can be subjected to seismic impact with a magnitude of 7 and higher, of which magnitude $7-51 \%, 8$ $-28 \%, 9$ and higher - 19\%. Maps of the seismic hazard in Bulgaria are generated at maximum acceleration, soil type A (according to the EC8 classification) for two occurrence periods of 95 and 475 years. The seismic hazard of Bulgaria (for both periods of occurrence) was determined mainly by seismic sources identified on the territory of the country and source Vrancea (Romania).

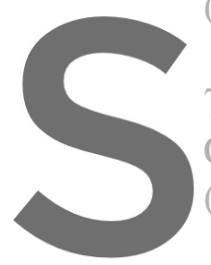

The most significant 7,2), Struma (04.04.19 Chirpan $(14.04 .1928$ (07.12.1986, magnitude 5 , Seismic design of Seismic design of bu earthquakes in B lgaria after 1900 ar
magnitude 0,8), Shabla (30.06.1
5,7), Pernik (22.05.2012. magnitude
ilding and facilities in Bulgaria over Shabla (31 03.1901 ,
ica (14.04.1913, mag
956, magnitude 5,5)
5,6). 1, ma
gnituc
ed as f Strajica

1) Until the beginning of 1957, the buildings (including different categories of the Bulgarian

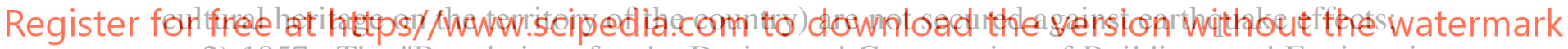
2) 1957 -The "Regulations for the Design and Construction of Buildings and Engineering Facilities in Seismic Areas" started, based on a seismostatistic zoning map, reflecting the observed intensities of the documented previous earthquakes;

3) 1961 and 1964- The map has a new edition concerning the reducing of the areas of the zones with intensity VII, VIII and IX;

4) 1977 - After the earthquake in Vrancea (Romania), new areas of VII and VIII intensity were added in the Danube area of Northern Bulgaria;

5) 1987 - A new seismic zoning of Bulgaria has been introduced;

6) January 2012 - A seismic zoning of Bulgaria is introduced based on the reference maximum acceleration.

It is possible to define five groups that account the year of design of the structure [2]:

- Very old (before 1919)

- Pre-code period (before 1920-1945)

- Low-code period (1946-1964)

- Moderate-code period (1964- 1987)

- Moderate to High-code period (after 1987)

In analyzing the conditions of Bulgaria to face a strong earthquake, we must note the 
following serious problems: 1) A large percentage of the available building stock was (including heritage buildings) designed and built before the new anti-earthquake standards of 1987, for very low levels of seismic provision; 2) There are no preventive measures taken for the preservation of discovered, preserved and restored archaeological structures, buildings and ensembles of national importance for the preservation of the movable historical and cultural heritage from the impact of the risk factors in general (earthquakes, floods, wind, temperature, etc); 3) Work is not being done to reduce or to stop the degradation of the existing building stock.

\section{SEISMIC PROTECTION AND STRUCTURAL INTERVENTIONS ON BULGARIAN HERITAGE BUILDINGS}

The paper is mainly dedicated to two groups of Heritage buildings: with masonry structure and with reinforced concrete structure.

The buildings with masonry structure are typical representative of the building typology from the end of 19th century and beginning of 20th century in the big cities of Bulgaria. Usually the masonry buildings have: 1) Deformable floor: timber floor and "Prussian vault" (steel structure) or 2) Reinforced Concrete floor. The first type has usually 1-4 storeys, the second type-1-5 storeys. Later, in the group of the Heritage buildings in the big cities, the reinforced concrete structures appeared. These buildings are mainly with frame structure and masonry infills.

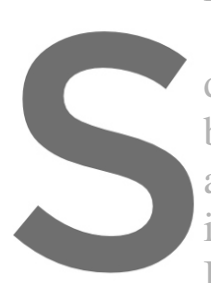

As noted in [3] with

distinguished: rehabilita

bearing capacity and

a change of function.

insulation, joinery, fl

In rehabilitation,
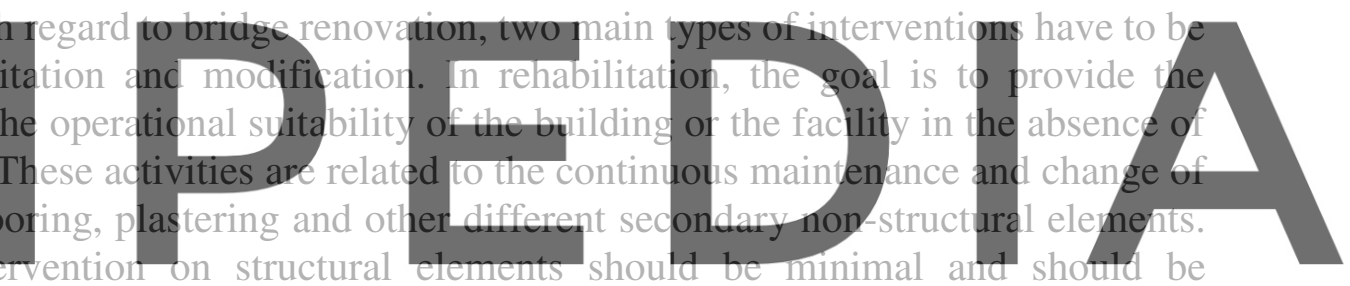

summarized in the reconstruction of damages resulting from aging, cracks, spalling of concrete,

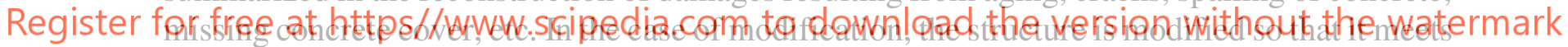

or performs the new load-bearing function. In this regard, it should be explicitly noted that this

approach encounters significant difficulties in providing the renovated structures with the requirements of contemporary seismic standards. The requirements of the Bulgarian regulations now set the conditions for the strengthened structure to meet the current standards. In practice, this often leads to the need for costly structural intervention that in fact underestimates the strengthening process and hence the maintenance of the existing building or facility.

\section{EXAMPLES FROM THE BULGARIAN PRACTICE}

The principles of the seismic assessment, outlined in the introduction of the paper, are illustrated by the following examples of procedures and recommendations dedicated to the extension of the service life of 3 Heritage buildings in Bulgaria. A very interesting example of the investigation and choosing the most appropriate method for rehabilitation of an industrial building structure is discussed in [4]. 


\subsection{Hotel "Lege Palace", Sofia, Bulgaria}

The first case study is dedicated to one of the emblematic buildings of Sofia-Lege Palace (Figure 1.).

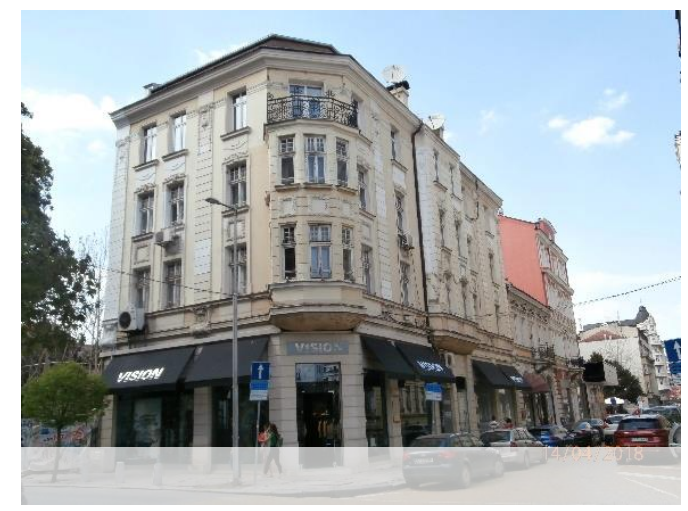

Figure 1: "Lege Palace" - actual view [11]

The analysed building is constructed in the period 1910-1914. The architectural design is realized by three famous Bulgarian architects: Georgi Fingov, Dimo Nichev and Nikola Uroukov.

The structure of the building has a typical masonry structure. The floors are constructed according to the system "Prussian vault": the main element is a steel double $\mathrm{T}$ flanged bean The concept of the syste the space between them stability of the structure, or if the support is an other steel beam, the col Figure 2 presents the architectural plan of the ground floor.

Register for free at https//www.scipedia.com to download the version without the watermark

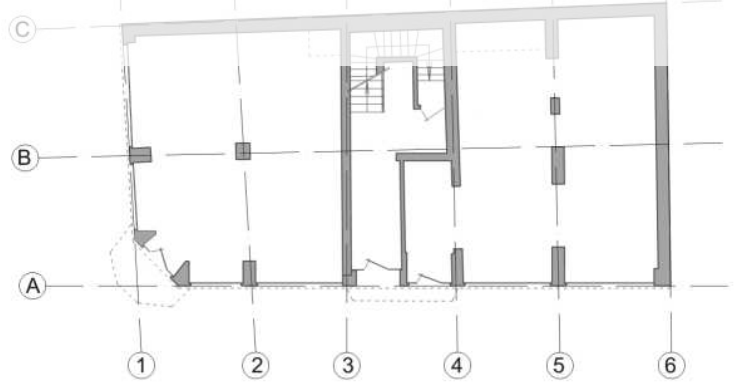

Figure 2: Plan of the ground floor (Lege Palace) [10]

The numerical analysis of the structure is provided by the program SAP2000 [5] based on FEM and a 3D model is defined (Figure 3.). The first step in the modeling is the definition of the characteristics of the materials. EC 6 [6] is the standard for the masonry structures and all the characteristics of the bricks are adopted according to the prescriptions of the standard. 


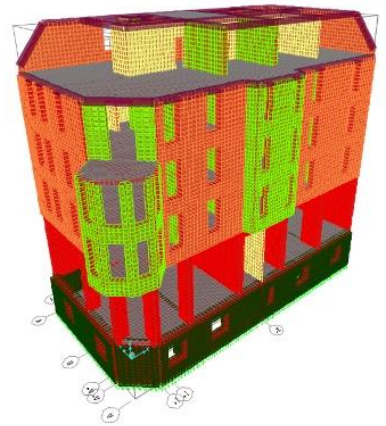

Figure 3: Numerical model in SAP2000 (Lege Palace) [5]

The next step in the numerical analysis is the definition of the loads EC 1 [7]. Three main types of loading are included: permanent loads $\mathrm{G}$, variable loads $\mathrm{Q}$, snow $\mathrm{S}$ and seismic load E. Two basic combinations are considered: the fundamental and the seismic.

Concerning the model, shell elements are used for the definition of the computational model. The contact of the structure with the foundations is assumed stiff. The thickness of the walls and the size of the structural elements are adopted according to the available drawings and the information from the site investigation. The floors are not a subject of the presented assessment and for that reason they are involved in the model in order to account for better distribution of the loading between the vertical elements and because of their snecific behaviour in the performance of the stiruct

The main results

forces in the vertical element

directions and axes.
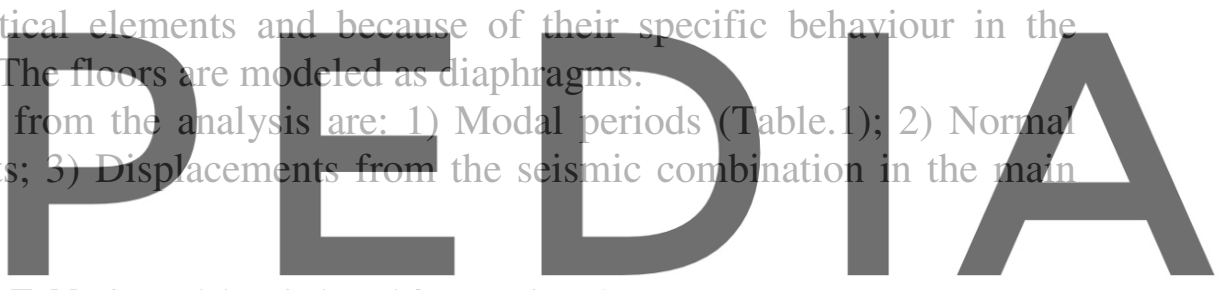

Table 1: Modal periods and frequencies [5]

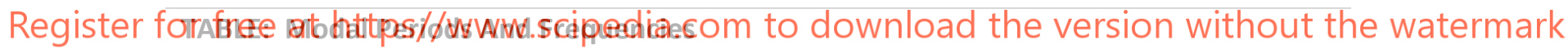
OutputCase StepType StepNum Period Frequency CircFreq Eigenvalue

\begin{tabular}{llrlrrr} 
Text & Text & Unitiess & \multicolumn{1}{c}{ Sec } & \multicolumn{1}{c}{ Cyc/sec } & rad/sec & rad2/sec2 \\
\hline MODAL & Mode & 1 & 0,9181 & 1,089 & 6,843 & 46,833 \\
\hline MODAL & Mode & 2 & 0,7910 & 1,264 & 7,944 & 63,103 \\
\hline MODAL & Mode & 3 & 0,5687 & 1,759 & 11,049 & 122,087 \\
\hline MODAL & Mode & 4 & 0,3626 & 2,758 & 17,328 & 300,252 \\
\hline MODAL & Mode & 5 & 0,2952 & 3,387 & 21,283 & 452,946 \\
\hline MODAL & Mode & 6 & 0,2791 & 3,583 & 22,510 & 506,697 \\
\hline MODAL & Mode & 7 & 0,2621 & 3,814 & 23,966 & 574,357 \\
\hline MODAL & Mode & 8 & 0,2402 & 4,163 & 26,157 & 684,178 \\
\hline MODAL & Mode & 9 & 0,2337 & 4,280 & 26,891 & 723,118 \\
\hline MODAL & Mode & 10 & 0,2261 & 4,424 & 27,795 & 772,543 \\
\hline MODAL & Mode & 11 & 0,2057 & 4,860 & 30,538 & 932,575 \\
\hline MODAL & Mode & 12 & 0,2008 & 4,980 & 31,291 & 979,112 \\
\hline
\end{tabular}


According to the standards in use, the checks for the displacements are basic for the assessment of the structural behaviour. Usually, for existing structures, the control of the damages as a result from excessive displacement are definitive for the behaviour. The results show that the displacements for the biggest part of the vertical elements (for the seismic combination) are not in the limits given in the standard. Analyzing the normal forces in the elements, it was found that the real value of the normal forces in the vertical elements also exceeds the maximum capacity of the elements.

In addition, analysis according to the actual Bulgarian regulations [8] is done. The same elements are checked. The results are similar but the safety according to EC8 [9] is lower than the safety according to the Bulgarian regulations [8]. The difference in the value of the modulus of elasticity of the bricks, defined in the two standards, leads to different stiffness of the walls. The ground floor has some previous interventions and after the site investigation was clear that some of the walls are removed in the past. This fact is related to the decreasing of the global stiffness of the structure. All changes in the first floor (produced on site without any specific design), representing removal of some brick walls, has unfavorable influence on the global seismic performance of the building. The actual conditions of the vertical elements after the onsite inspection shows that there are cracks and damages in them and they need special measures for strengthening.

The provided checks show that the building needs remedial measures for the damaged elements but any future changes in the structure will affect significantly the safety. It is not recommended to make any interventions without a special design for the strengthening. Special care is necessary for the foundations, The observed high level of moisture in the basement requires the execution

The results of the elements is reached a biggest part of the vertical elenents are bigger than
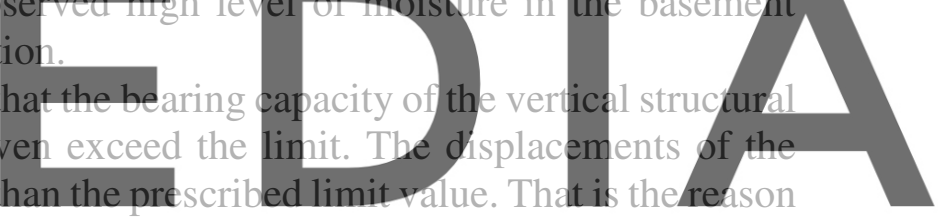

to recommend to the Investors to keep the structure without further changes and to strengthen

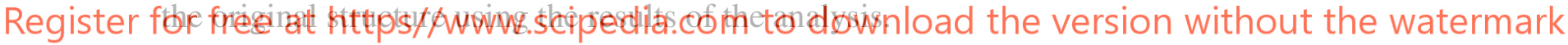

\subsection{Marine Station, Varma, Bulgaria}

The Marine Station in Varna is the biggest on the Black Sea cost in Bulgaria (Figure 4). The original design started in 1965. The construction of the building lasted from August 1966 until the end of 1968. The structure of the building is a classic monolithic reinforced concrete frame structure. The frames are designed in transverse direction. The distance between the frames is $9,00 \mathrm{~m}$. In the longitudinal direction the frames are connected with beams. According to the specific soil conditions, the foundation is realized with 150 driven piles. The length of the piles is $15 \mathrm{~m}$ and their cross section is $35 / 35 \mathrm{~cm}$. 


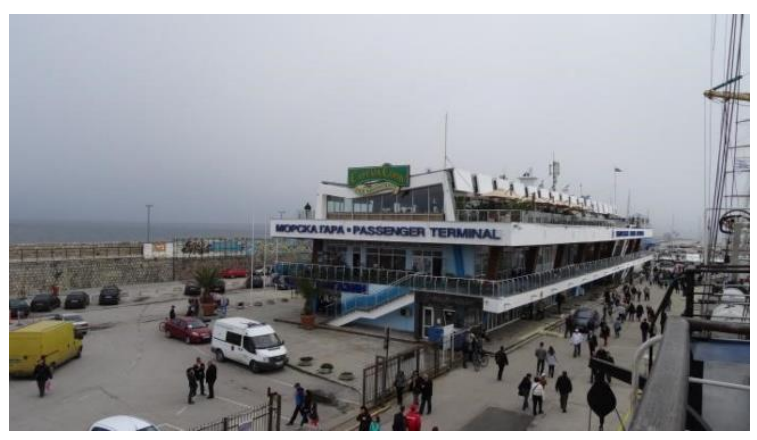

Figure 4: Marine Station, Varna - actual view [11]

For the structural seismic assessment a few numerical models in SAP2000 (Figure 5) are analyzed, using finite elements. The first 3 modal periods according to EC8 and the Bulgarian standards are practically the same. The elastic story drifts exceed the prescribed limits. The comparison is done according to EC8 [9] and according to the actual Bulgarian regulations [8].

The main checks for the structural elements - columns, beams, slabs, etc. show that the available reinforcement in some sections is not according to the contemporary standard requirements. The detailing of the structure is also not according to the standards.
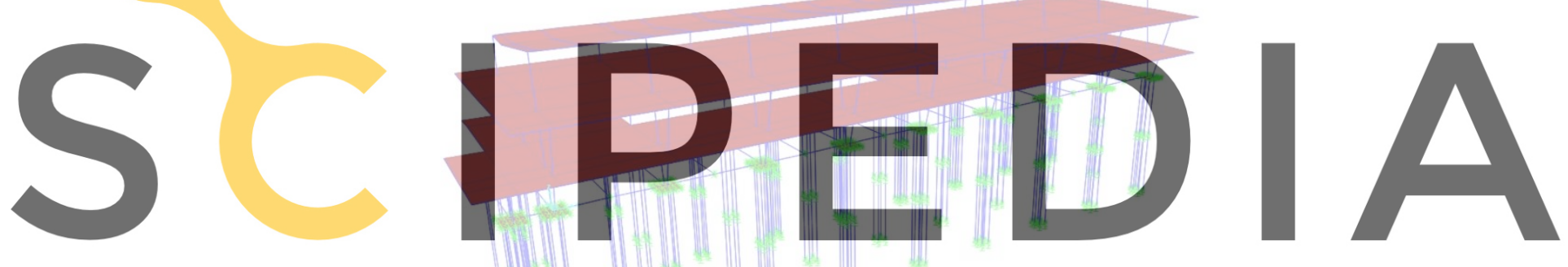

Register for free at https//www.scipedia.com to download the version without the watermark

Figure 5: Numerical model in SAP2000 (Marine Station) [5]

Despite the overall relatively good condition of the building, the structure is seriously endangered because of the very active processes of carbonization of the concrete and the reinforcement (Figures 6). The high level of carbonization results from the high humidity and the aerosol impact of seawater.

It is believed, that the building has exhausted its bearing capacity on the basis of the currently applicable regulations for the design of reinforced concrete structures and future functional changes are possible after strengthening of the existing structure. 


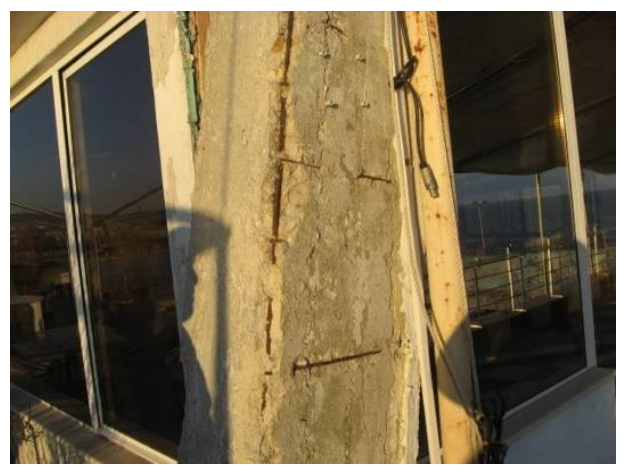

Figure 6: Actual condition of some structural elements [11]

It is believed, that the building has exhausted its bearing capacity on the basis of the currently applicable regulations for the design of reinforced concrete structures and future functional changes are possible after strengthening of the existing structure.

Adjusting the building structure according to the contemporary standards is not possible for the following reasons: 1) Actual condition of the construction materials; 2) Lack of precise information for the detailing; 3) The parameters of the seismic performance- modal periods, story displacements, are not in accordance to the prescribed recommendations and limits; 4) The numerical checks show that serious number of structural elements are at the limit of the load-bearing capacity determined by the standards or even exceed it by the effect of the various

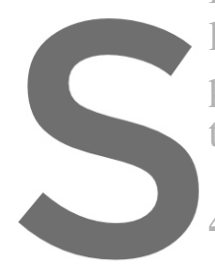
load effects and their combinations. Here, it is important to physical condition of the c the future activities. The 4.3 Serdica buildling in Sofia, Bullgaria
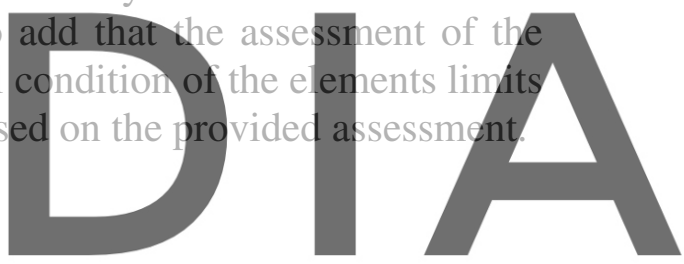

The Serdica building (Figure 7) is situated in the historical center of Sofia. The building is

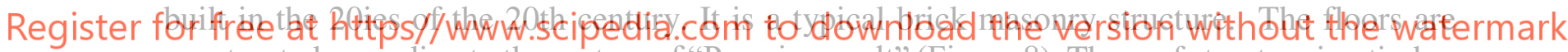
constructed according to the system of "Prussian vault" (Figure 8). The roof structure is a timber structure. The foundation is a dry stone masonry.

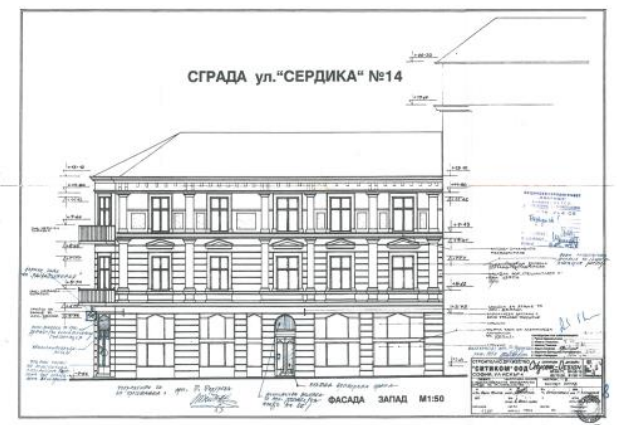

Figure 7: Serdica Building- main façade [10] 


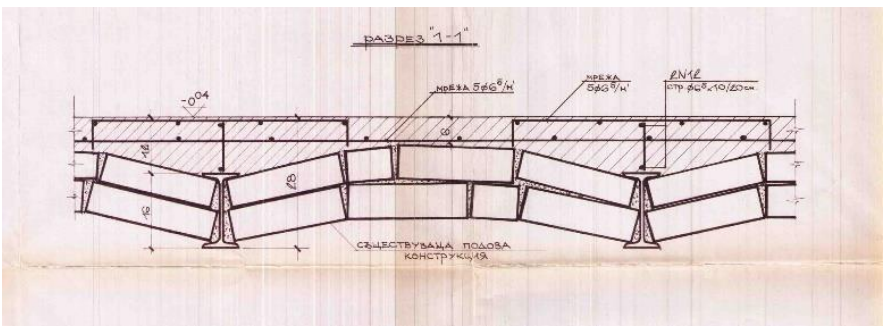

Figure 8: Strengthen floor structure "Prussian vault" (Serdica Building) [10]

After the visual inspection and according to the design documentation, the following conclusion can be drawn: many changes are realized in the long life of the structure. The seismic safety of the building is significantly deteriorated compared to the same at the time of construction.

This is to a lesser extent due to a deterioration in the characteristics of building materials as a result of aging and to greater changes, mainly in: 1) Increased weight of the structure, leading to increasing of seismic forces (new internal changes and additional intermediate level); 3) Contact between the new intermediate level with the existing structure; 3) Reduced stiffness after reduced length of the brick walls (in comparison of the original design), additional openings in the internal and external brick walls; 4) Unfavorable influence of the irregularity in the geometry and the distribution of the stiffness.

Similar to the previous cases, the future intentions of the Investor are limited and need a

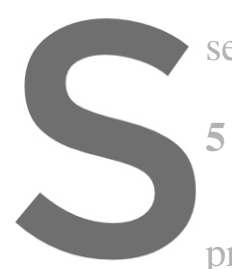
serious revision accordi

\section{S}

CONCLUSIONS A

The paper is presenti
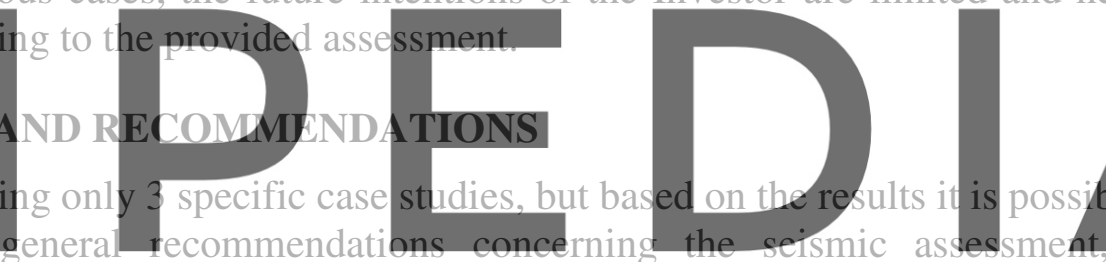

possibility to identify the vulnerability of historic structures and to give the recommendations

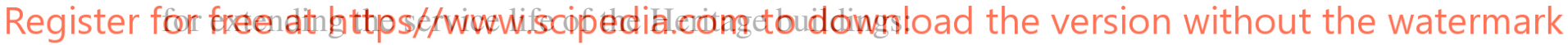

A greater problem lies in the fact that the vast stock of heritage buildings in the world does not conform to the requirements stipulated by current knowledge as necessary for seismic safety. The seismic upgrading of historic structures differs from that of more modern structures in that historic buildings do not have to conform to design codes and specifications which, thereby, are not applicable to such structures. More importantly, all seismic retrofitting must be reversible. A considerable difficulty in the practical application of the methodology for renovation of existing buildings and facilities of historical importance in Bulgaria is the lack of specially developed regulations for solving such problems. Some exceptions are the recommendations in Part 8.3 of the EC 8, which however are of a general nature and do not treat historical buildings. This complicates the work of structural engineers and forces them to apply existing rules designed for new buildings in solving the specific task described. As a general rule, the results are inadequate in relation to the intended purpose and the factual situation. It is necessary to develop specific national methodologies that distinguish between the design of new and the strengthening of existing buildings of historical importance.

- $\quad$ Historic structures have generally been constructed with basic building materials such as rock and stone, brick masonry and, in some cases, adobe or wood. The buildings 
made from these traditional materials usually possess strength but lack ductility, i.e. the capacity to undergo deformation without collapsing. Historic buildings tend to be massive and stiff structures made of brittle material.

- For some old structures, or buildings that may not allow major intervention, the possibility of providing base isolation may be envisaged. For historic structures which are not base-isolated, the necessity and economic feasibility of retrofitting (providing additional strength by using pre-stressed tie-rods, thin plates, buttresses, etc.) for seismic protection and risk reduction needs to be investigated.

- $\quad$ Any structural intervention must not, if possible at all, create aesthetic conflict. An unstated rule is that the retrofitting of historic structures be almost invisible.

- Material properties from the structure to be protected need to be assessed on the basis of accurate experiments. Sometimes for the initial assessment, it is possible to use some practical recommendations for the characteristics of the construction materials given in the standards.

- $\quad$ Adequate and realistic computer modelling of complicated historic structures requires significant designers' expertise. It is probably best to start with the simplest realistic model and then, if necessary, develop a model that reflects more structural features and complexity. Important aspects and considerations about the process of numerical modelling of structures that will be rehabilitated are presented in [12], despite that the example is not a historic structure.

- Seismic assessment of historic buildings remains a challenging task. There is a high level of complexity compared with the assessment of standard buildings. The heritage buildings are prone to collapse from seismic actions due to different types of seismic vulnerabilities. It is very important to find these vulnerabilities for the different types of structures and to find the specific mechanisms of failure.

\section{REFERENCES}

[1] Solakov D. Seismic mapping of Bulgaria according to Eurocode 8 with reporting the seismic hazard on the territory of the country, (2009)

[2] Kostov M., Kaneva A., Vaseva E., Stefanov D., Varbanov G., Koleva N. An advanced approach to earthquake risk scenarios of Sofia, International Conference on Civil Engineering Design and Construction, Varna, Bulgaria, pp. 245-251, (2006)

[3] Bruhwiler E. Extending the service life of Swiss bridges of cultural value. Engineering History and Heritage, Vol.165, issue EH4, pp. 235-240, (2012)

[4] Traykov A. contributor Rehabilitation of the Complex Reinforced Concrete Shell Roof Structure of an Industrial Building, Pelke E., Bruhwiler E. IABSE Structural Engineering Documents SED15: Engineering History and Heritage Structures - Viewpoints and Approaches, IABSE 2017, Zurich, Switzerland, pp.67-70, (2017)

[5] Sap 2000 - Computational program

[6] BDS EN 1996-1-1: Design of masonry structures - Part 1-1: General rules for reinforced and unreinforced masonry structures (EC 6)

[7] BDS EN 1991-1-1/NA: Actions on structures- Part 1-1: General actions -Densities, selfweight, imposed loads for buildings (EC 1) 
[8] Ordinance № РД-02-20-2/ 12.01.2012 and revised edition 2014 for the design in seismic regions

[9] BDS EN 1998-1: Design of structures for earthquake resistance- Part 1: General rules, seismic actions and rules for buildings (EC 8)

[10] Technical archives of Sofia Municipality - As built drawings

[11] Personal photo archive

[12] Traykova M., Boiadjieva R. Assessment and rehabilitation of the structure of existing reinforced concrete tank, $37^{\text {th }}$ IABSE Symposium, Madrid, Spain, pp. 543-549, (2014) 